\title{
LA IGLESIA DE CUENCA DURANTE LA II REPÚBLICA (1931-1936)'
}

\author{
POR \\ ÁNGEL LUIS LÓPEZ, VIILAVVERDE \\ Universidad de Castilla-La Mancha \\ C.E.U. "Cardenal Gil de Albornoz" (Cuenca)
}

\section{Resumen}

Este trabajo estudia la cuestión religiosa en una provincia eminentemente conservadora durante la $n$ República. Se analiza la actitud distante del obispo, D. Cruz Laplana y Laguna, ante el nuevo régimen, que se incrementa tras la expulsión de su amigo, el cardenal Segura. Se repasan tambiên las actividades de influencia eclesiástica (la promoción de actividades de culto, el fomento de las organizaciones del apostolado y la prensa) y la política religiosa del ayuntamiento conquense. Por último, se destaca la baja conflictividad religiosa en Cuenca, al menos hasta 1936.

\section{ABSTRACT}

The Church from Cuenca during the Second Republic, 1931 1936

This work studies the religious question in an eminently conservative province during the Second Republic. We analyce the distant attitude of the bishop, Cnuz Laplana, with regard to the new regime, that increased after the expulsion of this friend, the cardinal Segura. We also review the activities of ecclesiastic influence (the promotion of workship, the foment of religious organisations and the press) and the religious politics of the town council from Cuenca, at least until 1936.

1 Este artículo está basado en uno de los epígrafes de la tesis doctoral leída el 3 de diciembre de 1993 en el Departamento de Historia de la Úniversidad de Castilla-La Mancha bajo el título de Cuenca durante la II Repáblica: elecciones, partidos y vida política y dirigida por el Dr. D. Isidro Sánchez Sánchez.

La Iglesia en la Encrucijada Hispania Sacra 49 (1997) 
Durante la II República, Cuenca fue una de las provincias más conservadoras del país, lo cual la llevó a ser considerada como la "Covadonga del resurgimiento derechista español". Como quiera que tanto los partidos como los distintos grapos de interés fueron débiles, las redes caciquiles encontraron el terreno abonado para perdurar más tiempo que en otras provincias. $\mathrm{Y}$ en no pocas ocasiones condicionaron más los resultados electorales las presiones caciquiles y las directrices gubernativas que la voluntad de los ciudadanos ${ }^{2}$. partes.

En este contexto, hay que precisar cuál fue el papel de la Iglesia. Iré por

\section{ACTITUD DEL OBISPO ANTE LA SITUACIÓN POLÍTICA}

La proclamación de la II República, según Arbeloa, "cogió por sorpresa a la mayoría de los católicos"3. La postura de la Iglesia no fue unánime. Se apreciaron tres tipos de posicionamientos: aceptación legal (Vidal i Barraquer, Tedeschini), recelo (Irurita) y rechazo (Segura, Gomá, Múgica). Un sector amplio de la jerarquía, siguiendo las instrucciones del Vaticano de respeto del poder constituído, aceptó la legalidad ${ }^{4}$, aunque la reacción de los prelados ante el golpe de Estado de Primo de Rivera en 1923 había sido más entusiasta.

Desde el 26 de marzo de 1922 hasta su muerte, a los pocos días de estallar la Guerra Civil, fue obispo de Cuenca D. Cruz Laplana y Laguna (1875-1936). Durante los años de la Dictadura había entablado una relación de gran amistad con el alcalde Cayo Conversa ${ }^{5}$.

Según se desprende de la lectura del Boletín Oficial Eclesiástico del Obispado de Cuenca, el obispo de Cuenca tuvo una actitud inicial de moderación respecto a la instauración del régimen republicano, en sintonía con la postura mayoritaria de los obispos. En un documento publicado el 29 de abril titulado "En el momento actual", D. Cruz decía lo siguiente:

2 LÓPez VHLAVERDE, A. L. Pervivencias caciquiles y consenvadurismo en la provincia de Cuenca (1931-1936) : Añil, cuadernos de Castilla-La Mancha, 3 (1994), pp. 54-59.

3 ARBELOA, Víctor Manuel. Iglesia y república: diálogo imposible : 50 aniversario de la República de abril, Historia 16,60 (1981), p. 70.

4 Archivo Vidal y Bartaquer, Iglesia y Estado durante la II República Espaniola, 1931/1936, Monestir de Montserral 1971, Tomo Y, $1^{*}$ y $2^{\mathrm{k}}$ parte, p. 12.

5 MUELAS AlCOCER, D. Cruz Laplana y Laguna: obispo mátir de Cuenca, Cuenca 1992, p. 234. Este libro es poco fiable por tratarse de una hagiografia que incurre en graves errores históricos y no cita la fuente de procedencia. No obstante aporta algunas informaciones de interés que son poco accesibles a los investigadores laicos.

La Iglesia en la Encrucijada

Hispania Sacra 49 (1997) 
"Siendo los sacendotes ministros del Dios de paz es deber nuestro, conforme además con la doctrina de la Iglesia y de las indicaciones de la Santa Sede, cooperar a que esta paz se consolide en las parroquias y en la Nación mediante el acatamiento y respeto de todos los poderes consituídos, para el mantenimiento del orden y para el bien común $(\text {.... })^{\prime \prime 6}$.

A pesar de la moderada reacción inicial de D. Cruz, forzada por las circunstancias, la expulsión de España de su amigo el cardenal primado, Pedro Segura, le distanció más del nuevo régimen. La frecuente correspondencia privada que mantuvo con Segura para solidarizarse con él en su destierro lo sitúa en una línea ideológica no muy distante de éste. Segura había sido expulsado en junio como consecuencia de su enfrentamiento con el nuevo régimen y su alabanza de la monarquía en una pastoral en mayo. Según D. Muelas ${ }^{7}$, la amistad de Laplana con Segura venía desde unos años antes, al veranear asiđuamente éste en Cuenca. Pues bien, desde julio a noviembre, Segura contestó varias veces por correo a Laplana para manifestarle su agradecimiento. Muelas ha publicado fragmentos de las mismas -aunque sin citar su lugar de conservación- de las que, como muestra, reproduzco la más significativa, la de Hurt, en julio:

"Hurt, 17 de julio de 1931

Excmo. y Rvdmo. Sr. Obispo de Cuenca:

Mi venerado hernano y querido amigo: me apresuro a contestar sus bondadosas dos cartas últimas que tan sentidamente le he agradecido.

Puede suponer el consuelo que proporcionó en estos momentos una voz amiga y más, siendo tan pocas las que pasan a través de los Pirineos. Dios se lo ha de premiar largamente, como yo se lo pido, en justa recompensa a sus bondades"в.

$\mathrm{Si}$ acontecimientos como la quema de conventos, en mayo, y, poco después, la expulsión de Segura enturbiaron las relaciones de la Iglesia con la República, la Constitución y la legislación religiosa acabaron polarizando las posturas.

Antes del debate de la Constitución se produjo la movilización católica con la "pastoral colectiva del 25 de julio" que se publicó en agosto". Tenía la firma de los obispos, entre ellos la de monseñor Laplana, pero era obra del cardenal Segura desde su residencia francesa. Pedía la oración ante la situación dramá-

6 Boletín Oficial Eclesiástico del Obispado de Cuenca (B.O.E.O.C.), 8, (30 de abril de 1931).

7 MUELAS, D. Op. cit., p. 212.

8 MUELAS, D. Op. cit., p. 217. En las demás cartas, fechadas en septiembre (desde Paray le Monial), octubre (desde Lisieux) y noviembre (desde Vichy), se volvieron a repetir argumentos parecidos.

9 B.O.E.O.C., 16 (31 de agosto de 1931). 
tica de España y la sumisión filial a la jerarquía, y acusaba a la "mala prensa" de hacer campaña contra la Iglesia. El cardenal Vidal y Barraquer, que, aunque sin título alguno, será quien conduzca las riendas de la Iglesia española desde la expulsión del cardenal primado, consideró muy inconveniente esa pastoral dadas las circunstancias políticas españolas y así se lo comunicó a Segura. El texto fue muy mal recibido en ambientes políticos republicanos e incluso el Vaticano desaprobó la forma de llevar a cabo este documento ${ }^{10}$.

En diciembre del mismo año, monseñor Laplana publicó en su Boletín, sin hacer comentarios del mismo, un reglamento para la reorganízación económica de las parroquias como consecuencia de la reducción de la consignación al clero por parte del Gobierno ${ }^{11}$. Esta nueva organización se basaba en la siguiente estructura: la Junta Diocesana debía recaudar fondos, una Comisión Permanente se encargaría de ejecutar los acuerdos de la anterior, las Juntas Parroquiales (formadas por el párroco y señores) enviarían fondos a la primera, y unas Juntas Auxiliares, de señoras, promoverían donativos, limpieza, etc.

En los primeros meses del año siguiente, 1932, el Boletín empezó a llevar a cabo una labor que podríamos denominar como "pedagógica" - y que va a continuar en años sucesivos-, insertando una serie de disposiciones del poder civil que afectaban a la Iglesia para el conocimiento de los sacerdotes. Las disposiciones eran las correspondientes a la ofensiva gubernamental contra las órdenes religiosas tras la aprobación de la Constitución: libertad de cultos, instrucción religiosa en las escuelas, Tesoro Artístico Nacional, Venta y Gravamen de Bienes Eclesiásticos, entierros civiles, divorcio, ley de secularización de cementerios y enajenación de objetos artísticos centenarios. Dichas disposiciones, según palabras del obispo Laplana, atentaban directamente "a los sagrados intereses de nuestra santa Religión y de la Iglesia de nuestra Patria"12. La propia Constitución era también criticada por el obispo en lo relativo a los "artículos constitucionales no conformes con la doctrina o leyes católicas".

Pero también se aprecia una actitud moderadamente crítica del Boletín hacia el Gobiemo en artículos en los que, sin aparente relación con la problemática político-religiosa, se puede leer entre líneas una visión pesimista de la situación de la Iglesia como consecuencia de las circunstancias políticas. Así, en el documento "El mes de María", el obispo, después de referirse a que mayo era el mes de María y que ésta consolaba al pueblo cristiano, opinaba que "dificilmente se registrarán días más tristes y amargos en la historia de la Igle-

10 Archivo Vidal y Barraquer, Op. cit. T. Y., pp. 140-141.

1 B.O.E.O.C., 23 (26 de diciembre de 1931).

12 B.O.E.O.C., 1 (18 de enero de 1932).

13 B.O.E.O.C., 9 (14 de abril de 1932). Esta crítica la tomaba monsefior Laplana de las notas aparecidas en el Boletín Oficial de Tortosa. 
sia española que los días actuales, y esto nos obliga más y más a acudir a la medianera de todas las gracias...(María)"'14. Y, en una nota en la que se mencionaba la visita "ad limina" del obispo Laplana al Papa el día 7 de noviembre, se dice que siempre ha sido necesario visitar al Papa, pero aún más ahora "en que el horizonte se presenta preñado de nubes amenazadoras de horrorosa tormenta"15.

En noviembre de 1932, el obispo, tras recordar la obligación del pueblo cristiano acerca del sostenimiento del culto y de sus ministros, elaboró otro Reglamento, muy parecido al del año anterior pero ampliado en parte, incluyendo ahora los componentes de la Junta Diocesana ${ }^{16}$.

La labor pedagógica del Boletín y la moderada crítica a la situación políticoreligiosa continuó en 1933.

En enero de ese año, el obispo publicó una circular que llevaba el título de "sobre la enseñanza de la doctrina cristiana", y que justificaba en los siguientes términos:

\footnotetext{
"La necesidad imperante que las actuales circunstancias imponen de intensificar en sus parroquias la ensefianza del catecismo (...) Y ahora principalmente que por haber desaparecido la enseñanza del catecismo de la escuela oficial para concentrarse en nuestras iglesias, pesa sobre nosotros solos el deber de formar cristianos creyentes"17.
}

En abril de 1933 el obispo dio instrucciones al clero parroquial para poder hacer frente a algunos aspectos de la ley de secularización de cementerios. Estaban referidas a la incautación de cementerios parroquiales, para intentar que no afectara a todos ellos, y a la manera de hacer la declaración de voluntad sobre el enterramiento católico ${ }^{18}$. Y poco después, en agosto, aclaró la situación jurídica del enterramiento de religiosas ${ }^{i 9}$.

A fines de junio de 1933 aparecieron publicados en el Boletín tres textos de gran trascendencia para la Iglesia española: la encíclica de Pío XI, la Ley de Confesiones y Congregaciones Religiosas - sin comentarios- y la toma de posesión del nuevo cardenal arzobispo de Toledo, Gomá --de lo que se congratulaba la dirección del mismo- ${ }^{20}$.

\footnotetext{
14 B.O.E.O.C., 8 (30 de abril de 1932)

15 B.O.E.O.C., 21 (10 de noviembre de 1932).

16 Ibid.

17 B.O.E.O.C., 2 (31 de enero de 1933).

18 B.O.E.O.C., 7 (29 de abril de 1933).

19 B.O.E.O.C., 12 (31 de agosto de 1933).

20 B.O.E.O.C, 10 (30 de junio de 1933).
} 
En 1934, el Boletín siguió en la misma línea. Merece la pena destacar el documento del obispo relativo a la subida de la "tasa de las misas manuales" a 3 pts para "hacer más llevadera la santā pobreza sacerdotal (...) en vista de la situación cada vez más angustiosa que atraviesa el clero diocesano, despojado de sus haberes sin una compensación adecuada (...)"21. Precisamente en el mismo número se publicó la "Ley de Haberes Pasivos", que pretendía paliar la penosa situación económica de la Iglesia.

Durante el año siguiente el Boletín ofreció pocos cambios. Continuó la "labor pedagógica" aclarando cómo se había de levar la "contabilidad de órdenes y congregaciones religiosas"22, o qué modelo de instancia había que solicitar para la declaración de cementerios privados ${ }^{23}$.

Sin embargo, la actitud del obispo, expresada a través del Boletín y de correspondencia privada, cambió desde los primeros meses de 1936: sintió temor ante la marcha de los acontecimientos, que aumentaba con el paso de los meses y con hechos, que ya comentaré, como el del saqueo de los Paúles. D. Muelas recoge los siguientes testimonios:

\footnotetext{
"Momentos son estos de angustia y zozobra por lo que a nuestra Patria se refiere, y es necesario de todo punto, que redoblemos nuestras súplicas hasta el trono de la divina Misericordia pidiendo sus luces y sus alientos para conducimos como buenos en el cumplimiento de su deber..." (Boletin Oficial del Obispado de Cuenca, 31 de enero de 1936)

"El 20 de mayo, a las damas de la corte de la Virgen del Pilar, les hablaba de la virtud de la fortaleza necesaria especialmente en los momentos graves de la persecución...para resistir convenientemente durante la tempestad que amenazaba a España.

En junio decía en una carta:

No podemos prever a donde (sic) nos llevarán...Los efectos serán más desastrosos que en 1931'24.
}

En definitiva, monseñor Laplana mantuvo una posición distante del nuevo régimen, que contrastaba con la que había seguido en la época de la Dictadura. Aunque no hay constancia de enfrentamientos o tensiones con los poderes públicos provinciales o locales, sí quedan testimonios críticos hacia ciertos acontecimientos o leyes relacionadas con la política religiosa, como la expulsión de Segura, algunos artículos de la Constitución o las leyes posteriores. Naturalmente, no expresó el mismo tono crítico en la correspondencia privada que en su Boletín, debido al carácter más oficial de éste. Y ya en meses previos

21 B.O.E.O.C. 6 (30 de junio de 1934).

22 B.O.E.O.C., 1 (31 de enero de 1935).

23 B.O.E.O.C., 2 (28 de febrero de 1935).

24 MUELAS, D. Op. cit., p. 324.

La Iglesia en la Ercrucijada Hispania Sacra 49 (1997) 
a la guerra, llego a sentir miedo ante el cariz que tomaban los acontecimientos. Miedo justificado porque fue asesinado en agosto de 1936.

En cualquier caso, a pesar de que el obispo no se inmiscuyó en los asuntos políticos locales, sin embargo no podemos menospreciar la influencia de todo lo religioso en la vida pública de una provincia tan conservadora como la conquense.

\section{ACTIVIDADES DE INFLUENCIA ECLESIÁSTICA}

Voy a tratar aquí brevemente tres temas: la promoción de actividades de culto, el fomento de organizaciones de apostolado y, por último, de la prensa como órgano del mismo.

La promoción de actividades de culto era esencial en una época en que la Iglesia se sentía perseguida. Como señala $\mathbf{M}^{\mathrm{a}} \mathrm{J}$. Moreno Beteta, "se notaría la influencia política en las públicas manifestaciones de las mismas [actividades] o en la reclusión a los templos. En el bienio cedista se revisten de un halo de solemnidad y prestigio social" ${ }^{25}$. Se pueden agrupar estas actividades en las siguientes:

- Beatificaciones: el día 20 de mayo de 1933 fue beatificado el jesuíta Juan del Castillo en Belmonte, de donde era originario, con una ceremonia solemne ${ }^{26}$.

- Devociones a María y al Santo Rosario: los días más celebrados en Cuenca, incluso durante estos años, fueron el de la Purísima y la Inmaculada, fechas en los que el obispo animaba a los fieles a participar. Y, para ratificar la importancia que al culto mariano concedía D. Cruz, fomentó la devoción al rezo del Santo Rosario ${ }^{27}$.

- Procesiones: tanto las de Semana Santa como las del Corpus se celebraron todos los años. Tan sólo se diferenció su celebración de las de años anteriores en que a veces se cambió el itinerario u horario de alguna procesión o se denegó la presencia gratuita de la banda de música. La Semana Santa conquense era la celebración religiosa de más larga tradición, de más participación ciudadana - prescindiendo de sus ideas políticas-y de más ardua preparación organizativa. La Cámara de Comer-

25 Moreno Beteta, María Jesús. Presencia de la Iglesia en la vida cultural del Ciudad Real de la II República: I Congreso de Historia de Castilla-La Mancha, Toledo 1988, T. X, p. 243.

26 MUELAS, D. Op. cir., pp. 151-152.

27 MUELAS, D. Op. cit., pp. 155-163. 
cio e Industria de Cuenca Juchó en todo momento para que se celebrase con la solemnidad de siempre y empleó para su defensa, más que argumentos religiosos, motivaciones eminentemente turísticas.

Lo que resulta evidente es que no hubo incidentes reseñables durante las procesiones de Semana Santa. No hay más que ver lo que decía al respecto Antonio Guaita, antiguo presidente de la Cámara de Comercio e Industria, en una de las actas de la misma. El Sr. Guaita contestaba al presidente y al secretario de la Cámara, que temían trastornos graves provocados por extremistas políticos en la Semana Santa de 1933, y les decía que no había motivo para sustentar tales temores porque "el elemento obrero de Cuenca figura como cofrade o como voluntario portador de pasos en todas las procesiones (...)"28. Incluso en 1936 se celebraron dichos desfiles procesionales.

La Iglesia conquense, al igual que en el resto de España, se dedicó al fomento de organizaciones de apostolado. Las más importantes fueron aquí la Acción Católica y, muy vinculadas a ella, la Asociación Católica de Padres de Familia, así como la Asociación de Estudiantes Católicos y, por último, la Cofradía o Asociación de la Doctrina Cristiana.

La Acción Católica se reorganizó en Cuenca a fines de 1926, poco después de publicar el cardenal Segura la pastoral "Principios y bases de Reorganización de la Acción Católica Española". Desde entonces, el obispo conquense dedicó gran parte de sus esfuerzos a la extensión de la AC en Cuenca (sirviéndose de sus sacerdotes para que la organizaran en sus parroquias) ${ }^{29}$. Pretendía que, bajo la dirección de la jerarquía eclesiástica, se formasen grupos de seglares selectos que influyeran en las escuelas y en la enseñanza religiosa. Su actuación debía ser a "todos los niveles, sociales, familiares y personales"30. Años despues, en octubre de 1931, ya en la II República, nació su órgano de expresión, El Defensor de Cuenca.

Durante el primer bienio republicano, en un contexto político caracterizado por las malas relaciones entre los poderes civil y religioso, la AC estuvo desorganizada y fue la jerarquía la que canalizó la reacción defensiva. Sin embargo, la situación empezó a cambiar a raiz de la aprobación de las Bases de reorganización de la AC y su posterior difusión a lo largo de 1932. Entre febrero y octubre de 1933 la nueva Junta Central, presidida por Angel Herrera, inició una nueva reorganización de la AC desplegando una intensa actividad propagandística. En este contexto hay que inscribir las charlas de Angel Herre-

28 Libro de Actas de la Camara de Comercio e Industria, 31 de enero de 1933.

29 MUELAS, D. Op. cit., pp. 116-1 17.

30 Muelas, D. Op. cir., pp. 116-117.

La Iglesia en la Encrucijada Hispania Sacra 49 (1997) 
ra en Cuenca tras ser invitado por el obispo. El día 30 de abril de 1933 pronunció tres conferencias presididas por monseñor Laplana en el edificio de la Merced: una a los sacerdotes y seminaristas (les invitó a intensificar la propaganda de la AC), otra a los padres de familia -les habló de la amenaza del sectarismo y les pidió que defendieran la enseñanza religiosa - y la última a las Juventudes Católicas ${ }^{31}$.

El año 1934 fue el de la consolidación de la Acción Católica en España, debido al cambio de orientación política de la República. La labor de la AC conquense no se limitó a la organización del "Día de la Prensa Católica"32 sino que se amplió a la Semana "Pro Ecclesia et Patria", celebrada en todas las diócesis como reacción frente a la Ley de Confesiones y Congregaciones Religiosas y dirigida a los intelectuales para reivindicar la aportación histórica de la Iglesia en la historia de España. Se celebró del 10 al 16 de diciembre en la iglesia parroquial de $\mathrm{S}$. Esteban y estuvo dedicada a la figura del cardenal Gil de Albornoz, un "conquense de nacimiento y de familia, personaje destacado en la historia del siglo XIV". Entre los conferenciantes estuvo el dirigente de Renovación Española y diputado derechista por Cuenca, Antonio Goicoechea, lo que da idea de la politización de estas conferencias. Como complemento a las mismas, hubo charlas particulares para el clero, para señoras y mujeres jóvenes, y para jóvenes católicos.

En 1935 los dirigentes locales de la AC organizaron la "Jornada de Acción Católica en Cuenca"33, cuya finalidad era doble: religioso, por un lado - triduo los días 12, 13 y 14 de junio en la iglesia de $\mathrm{S}$. Esteban sobre el apostolado de $\mathrm{AC}$, su organización y su relación con la jerarquía eclesiástica- $-\mathrm{y}$, por otro, profano y social - hubo un discurso y un auto sacramental en el teatro Cervantes el 15 de junio-. La Jornada terminó el 16 de junio con la misa de comunión y la bendición de la bandera de la Juventud Masculina.

Conocemos también por la prensa la existencia de la Asociación Católica de Padres de Familia, aunque no el año de su constitución. Esta asociación organizó varias conferencias en 1933. En julio, en el salón de la Merced, el Padre Paúl Enrique Albiol habló de la educación religiosa como "arma imprescindible para obtener el triunfo sobre la pública inmoralidad" y que la supresión de la misma se apoyaba en el sectarismo ${ }^{34}$. En septiembre, el mismo sacerdote se dirigió a esta misma asociación e insistió en argumentos pareci-

\footnotetext{
31 MUELAS, D. Op. cit., p 277.

32 B.O.E.O.C., 12 (31 de diciembre de 1934).

33 B.O.E.O.C., 4 (31) de mayo de 1935).

34 El Defensor de Cuenca, 79 (22 de julio de 1933).
} 
dos, criticando la enseñanza laica y exhortando a los padres católicos para que sus hijos estudiaran en escuelas y centros superiores católicos ${ }^{35}$.

A fines de ese año, tras el triunfo electoral de las derechas, la Asociación Católica de Padres de Familia intensificó la propaganda en pueblos de la provincia para pedir al Gobierno que las escuelas fueran religiosas, se respetaran las creencias de los demás y se abrieran en Cuenca dos escuelas católicas, y solicitar al gobernador que los entierros se celebraran católicamente ${ }^{36}$.

La Asociación de Estudiantes Católicos es nombrada por primera vez en la prensa conquense en febrero de 1933, con motivo de una polémica con la otra asociación de estudiantes rival, la FUE (Federación Universitaria Escolar) ${ }^{37}$. Celebró el 9 de febrero de 1934 una Junta General Extraordinaria para organizar definitivamente la Asociación, lograr una mayor eficacia en los postulados que defendía y elegir un nuevo equipo directivo. El anterior presidente, Fernando Flores -elegido ahora presidente honorario-, era relevado por Juan Martino Casamayor, quien se rodé en la nueva junta directiva de bastantes mujeres en cargos secundarios ${ }^{38}$.

En enero de 1933, a través de la publicación de la circular "sobre la enseñanza de la doctrina cristiana" - de la que ya hablé anteriormente-, el obispo conquense daba instrucciones para la fundación de la Cofradía o Asociación de la Doctrina Cristiana - cuyo órgano de expresión sería la hojita La Voz del Catecismo-, la regulación de la catequesis y la constitución de "escuelas parroquiales de la doctrina cristiana" distintas de la catequesis parroquial ${ }^{39}$.

En cuanto a la importancia que la Iglesia otorgaba a la prensa como 6rgano de apostolado, queda clara con la celebración anual de "El Día de la Prensa Católica", organizado por la Junta Diocesana. En efecto, un día al año se dedicaba a celebrar, fomentar y centrar la atención sobre la prensa católica, que representaba a la "buena prensa", en contraposición con la "mala prensa" o prensa antirreligiosa. Es, como señala $M^{\mathrm{a}}$ Jesús Moreno Beteta, reflejo de la "actitud combativa de una Iglesia que se siente perseguida y que utiliza la prensa para difundir sus ideas sobre la enseñanza, la estructura social, el origen

35 El Defensor de Cuenca, 88 (23 de septiembre de 1933).

36 El Defensor de Cuenca, 105 ( 30 de diciembre de 1933).

37 La Opinion, 1.233 ( 7 de febrero de 1933 ).

38 El Defensor de Cuenca, 113 (24 de febrero de 1934). La junta directiva de la Asociación de Estudiantes Católicos estaba compuesta por: Juan Martino Casamayor (presidente), M Carmen Lucas (vicepresidente), Federico Rodríguez (secretario), $\mathrm{M}^{\mathrm{a}}$ Nieves Lucas Escamilla (vicesecretaria), Mariano Echavarria Ramos (tesorero), Soledad Rubio (vicetesorera), $M^{*}$ del Remedio Adalid (bibliotecaria), M" Pilar Gallardo (vocal), Mercedes Porta (vocal), David Villalba Martinez (vocal), Jose Godoy Olivares Martínez (vocal) y Eduardo O'Kelly (vocal).

39 B.O.E.O.C., 2 (31 de enero de 1933). 
del poder, el derecho al propio magisterio, la indisolubilidad del vínculo matrimonial, etc., creando estados de opinión que garanticen la adhesión popular a la jerarquía eclesiástica"40. Desde su llegada a Cuenca como obispo, D. Cruz, según señala D. Muelas, dedicó una especial atención a este día ${ }^{41}$.

\section{POLfTICA RELIGIOSA DEL AYUNTAMIENTO DE LA CAPITAL}

Salvo medidas aisladas, se puede decir que el anticlericalismo de algunas propuestas municipales se quedo prácticamente en papel mojado. Aunque hubo ciertos debates entre los concejales en los que se apreciaban ideas anticlericales - algunas veces muy extremas-, como era habitual en los ambientes izquierdistas de la época, éstas no se concretaron realmente. Ni siquiera en los primeros meses de 1936 (poco después de ser repuestos los concejales izquierdistas, que fueron propicios para la radicalización de los planteamientos anticlericales entre los concejales republicanos y socialistas) se encuentran medidas llevadas a la práctica que pudieran considerarse demasiado ofensivas contra la Iglesia, sobre todo si se compara Cuenca con otras localidades españolas.

El primer acuerdo de política religiosa tomado por el municipio fue como consecuencia de las disposiciones de secularización de cementerios. En noviembre de $1931^{42}$ el ayuntamiento aprobó por unanimidad la desaparición de la tapia que diferenciaba el cementerio civil del católico y el cierre de la puerta de aquél para que no hubiera separaciones ni signos de distinción entre ellos. En relación a los cementerios civiles, parece ser que ya desde las primeras semanas del nuevo régimen, el Ayuntamiento conquense dio más facilidades para los entierros civiles, lo que contrastaba, según el decenario izquierdista Electra $^{43}$, con lo que sucedía durante la Dictadura.

Dos meses después, el 30 de enero de 1932, los diputados aprobaron la ley de secularización de cementerios, que completaba las anteriores disposiciones. Entre otras cosas, declaraba comunes los cementerios municipales, sin diferencias confesionales, concedía a los municipios la potestad de incautar cementerios parroquiales y establecía que el fallecido debía declarar en un acta notarial su voluntad de ser enterrado religiosamente. Ya vimos como en abril de 1933, D. Cruz Laplana, preocupado por dicha ley, dio instrucciones para los entierros de religiosos. Sin embargo, no parece que su aplicación contentara en Cuenca a los más encarnizados anticlericales, ya que en febrero de 1936 el Ayuntamiento

40 MOREno Beteta, M. Jesús. Art. cit., p. 246.

41 MUELAS, D. Op. cit., p. 125-132.

42 Libro de Actas del Ayuntamiento de Cuenca (L.A.A.C.), 9 de noviembre de 1931.

43 Electra, 36 (21 de abril de 1931) 
aprob6 por unanimidad las propuestas de la minoría socialista para que se cumpliera la citada ley ${ }^{44}$-lo que indica que, hasta entonces, no se había cumplido totalmente- - solicitar al gobernador que no se autorizaran entierros por la vía pública. Y, a pesar de su aprobación, un mes después el alcalde, Alfredo García Ramos, dio largas a la pregunta de un concejal sobre si se había quitado ya la cruz del cementerio y contestó que se habían tomado muchos acuerdos y había que establecer un orden de prelación ${ }^{45}$. Ya no se vuelve a hablar en las actas municipales de este tema.

En cuanto a las procesiones de Semana Santa, ya comenté cómo el Ayuntamiento las autorizó e incluso dio subvenciones a la Cámara de Comercio para que las organizara desde el primer año. Pues bien, en febrero de 1936, dentro del mismo paquete de propuestas de la minoría socialista expuesto antes, el consistorio conquense aprob6 solicitar al gobernador que no autorizara procesiones por vías públicas.. No obstante, al mes siguiente, el mismo Ayuntamiento, con la oposición de algunos ediles, decidió autorizar los desfiles procesionales de Semana Santa (aunque la banda de música no sería gratuíta y no se concederían subvenciones a la Cámara de Comercio e Industria para su organización) porque, segun el alcalde, se trataba de fiestas profanas y no religiosas $^{46}$.

De modo que la única medida puesta en práctica que se puede considerar como verdaderamente ofensiva a la Iglesia por parte del Ayuntamiento fue la prohibición del culto en la ermita de San Antón en mayo de 1932. La justificación de la misma, según los concejales que presentaron la moción, estaba en las denuncias repetidas de que en el púlpito se hacía propaganda de ideas políticas, "faltando con ello al respeto de debe merecer a todos el sitio de referencia y muy especialmente a quienes se titulan sacerdotes de la Religión". En un principio se aprobó por unanimidad, aunque en la sesión siguiente, dos ediles derechistas que no habían estado presentes en la sesión anterior votaron en contra ${ }^{47}$.

\section{4. ¿CONFLICTIVIDAD RELIGIOSA EN CUENCA?}

A pesar del panorama tan apocalíptico que sobre la situación de la Iglesia conquense durante estos años traza Domingo Muelas, no puede hablarse seriamente de una situación de conflictividad religiosa excesiva -al menos hasta

44 L.A.A.C., 24 de febrero de 1936.

45 L.A.A.C., 23 de marzo de 1936.

46.A.A.C., 16 de marzo de 1936.

47 LA.A.C., 17 de mayo y 21 de mayo de 1932.

La Iglesia en la Encrucijada Hispania Sacra 49 (1997) 
1936 - en una provincia como ésta, eminentemente conservadora y conocida en España por sus veleidades derechistas; y máxime si la comparamos con la situación en otras provincias.

Un ejemplo claro de esto está en la celebración,sin apenas incidentes, de las procesiones de Semana Santa a lo largo de estos años.

En la provincia de Cuenca no hubo durante la II República nada más que dos hechos conflictivos: el incendio de la iglesia de Torrecilla y, sobre todo, los sucesos del primero de mayo de 1936 en el convento de los Paúles en la capital.

La Iglesia de Torrecilla, un pueblo de apenas 225 habitantes, ardió, como señala D. Muelas, en la madrugada del 6 de agosto de 1932. Este autor afirma que el incendio fue provocado ${ }^{48}$, pero no hay pruebas de ello y, en su día, se consideró un suceso fortuito.

El segundo hecho fue el más grave. El 1 de mayo de 1936, en plena huelga general y en vísperas electorales, un grupo de sindicalistas asaltaron el convento de San Pablo y lo saquearon -destruyeron su magnífica biblioteca- tras correrse el rumor de que los monjes habían efectuado disparos e iban a evitar que se votara. Como consecuencia de ello huyeron la mayor parte de los frailes y, según Muelas, algunos fueron maltratados ${ }^{49}$. Este autor hace hincapié, pues, en los efectos destructivos sobre el convento y en la vejación recibida por los frailes. Una visión totalmente distinta la proporciona el semanario izquierdista Heraldo de Cuenca, que considera el incidente como una "provocación intolerable de los paúles" y justifica su abandono de la ciudad "para evitar hechos de violencia y tranquilizar a la población"so.

Fue ésta la excepción que confirma la regla, en momentos muy conflictivos, marcados por una apretada lucha electoral y una aguda polarización de la situación social y política. Hasta los comienzos de la inmediata Guerra Civil no se puede hablar de una conflictividad religiosa patente en Cuenca, que tuvo su máxima expresión con el asesinato del obispo Laplana en el verano de 1936.

48 MUELAS, D. Op. cit., p. 322.

49 MUEl.AS, D. Op, cif., p. 328-329.

so Heraldo de Cuenca, 71 (4 de mayo de 1936). Por último también también recoge el incidente el Diario de Sesiones de las Cortes, 37 (1 junio 1936), p. 266. 